New Zealand journal of industrial relations, 1983, 8,107-112

\title{
Some crucial issues concerning the safety provided by occupational health standards
}

\author{
Tord Kjellström*
}

Traditionally occupational health standards for chemicals and other hazards in the workplace have been established by "expert committees" with no involvement of the victims of the effects of the hazards, namely the workers themselves. This has led to standards that do not protect workers against all ill effects. The example of trichloroethylene is typical. The New Zealand standard lags behind the World Health Organisation and Swedish standards. Workers have a moral right to be involved in the standard setting and the enforcement procedures. The crucial issue for them is the definition of the "acceptable risk" for a particular hazard, as they are putting their own health at stake. It is 34 years since Sweden established the system of workers health and safety representatives in all workplaces and in government agencies dealing with occupational health. Maybe it is time for New Zealand to follow this example.

\section{Introduction}

Occupational health standards are a fundamental part of any programme for preventing ill health and injuries caused by hazards in the workplace. There has been little public discussion about such standards in New Zealand and only in the last few years has the Department of Health involved representatives of the victims of work hazards in the standard setting procedures. This paper considers some of the lessons to be learnt from overseas experience in this field and suggests some ways by which workers and their organisations can ensure that work hazards are adequately controlled.

At a workshop on occupational health standards in Canada, SOEH (1979) some years ago, different aspects of the procedures for setting standards were discussed. The need for increased worker involvement was pointed out by several speakers. Dr Eula Bingham, then Director of the United States Occupational Safety and Health Administration (OSHA), put it this way: "workers need to be there when you make decisions in order to remind you that it is their lives you are dealing with".

Before occupational health standards can be set one has to define the purpose of the standards. Naturally the purpose should be to protect the workers' health, but this general aim can be interpreted in different ways. The United States Occupational Safety and Health Act states that "no employee should be harmed by the working environment during his/her whole lifetime". If this is going to be achieved, the standard itself has to be sufficiently protective, it has to be maintained and updated and it has to be enforced. The procedures with which the standards are met in the individual industry have to be reliable. It is generally agreed that engineering controls are more reliable than personal protection in decreasing individual worker's exposures (Ashford, 1979).

A seemingly less strict approach is used in the United Kingdom where the "purpose of

* Senior Lecturer in Occupational Health, Department of Community Health, University of Auckland. 
the standard is to achieve lower exposure than what would have happened without the standard" (Locke, 1979). Locke, who was then the Director of the Health and Safety Executive (the occupational health administration in the United Kingdom), also stated that he felt there was no point in making a standard stricter, when industry is not complying with present standards.

\section{Current preventive approaches}

The United Kingdom, New Zealand and Australia have adopted the standards proposed by the American Conference of Governmental Industrial Hygienists (ACGIH, 1982a) as official standards. These are not intended to protect all workers against all effects. The ACGIH standards are basically a list of recommended maximum concentrations of chemicals in the air.

A standard can be more elaborate than a number, e.g. a set of guidelines for procedures to limit worker exposure to hazards (or a "code of practice"). The elaborate standards now promulgated by OSHA (e.g. the standard for lead (OSHA, 1978)) are quite different from the 1-number standards listed in the Threshold Limit Values (TLV) publication from the ACGIH (1982a). However, even the more elaborate standards will have to be based on numbers that give guidelines for permissible concentrations of the chemicals in air or in biological materials (blood, urine, etc.). Indeed, the new OSHA lead standard describes certain concentrations as maximum concentrations. It also states how these concentrations should be measured. This is an important advancement, because earlier standards have often been open to different interpretations, depending on the way the concentrations were measured. The new OSHA lead standard includes rules for worker involvement in the monitoring of the working environment and enforcement of the standard as also for the workers' rights to financial compensation in case the enforcement of the standard affects his/her livelihood.

Certain chemicals occur not only in the workplace environment but also in ambient air or in food. Lead is a good example of such an ubiquitous element. The occupational standard must allow for the additional exposures from non-work sources. Some work hazards interact with life-style factors, such as smoking. The joint effects of asbestos and smoking, for example, are well documented (Hammond et al., 1979). In order to give protection to all workers the occupational standard has to be low enough to give acceptable protection also to the smoking worker.

\section{Workers' rights}

The workers basic rights acknowledged in the OSHA standard setting procedure are: (1) the right to refuse dangerous work; (2) the right to complain about conditions; (3) the right to insist upon inspection by experts and (4) the right to access to one's own health and exposure data (Bingham, 1979).

In the United States these rights have been formalised into regulations and laws. In New Zealand the new Factories and Commercial Premises Act does not spell out workers' rights in this way. The Act acknowledges workers' right to a work environment which does not cause ill health and which is not offensive, but no mention is made of workers involvement in standard setting.

One basic problem for workers is the lack of information about the chemicals used in industry. Often the identity of the chemicals is withheld from the workers who handle the chemicals and they have no way of knowing what types of health effects to expect. Legally established rights to get access to this type of information are necessary. A number of information systems on health effects of chemicals are being set up at the moment by international organisations (such as ILO, UNEP, WHO, etc.), but these are of limited value if workers do not know which chemicals they are exposed to. 
Workers should have a right to interpret the toxicological data from their standpoint as the potentially affected. Such interpretation is a very important step in standard setting. Workers should also have a right to take part in the enforcement and monitoring of their own environment. In some countries these rights have already been acknowledged through legislation (e.g. Sweden's Work Environment Act 1977).

\section{Criteria for acceptability of a standard}

One of the key issues in the interpretation of information on toxicology of a particular chemical hazard is the criteria for acceptability of a standard. Based on dose-response relationships, it is possible to estimate the proportion of workers expected to be affected by a particular hazard after a particular duration of exposure. The question is, should we put the standard at a point where 10 percent of the workers are affected, where 1 percent are affected, or where 0.1 percent are affected?

Certain hazardous materials can be completely banned, but this may not eliminate all exposures. One example is asbestos, the use of which decreased drastically in Sweden after very restrictive regulations were passed (Englund, 1979). The existing asbestos insulation installed in earlier years is however, still there, and exposed to workers carrying out repairs or replacements of insulation material. This is a major problem in New Zealand. Another example is lead in paint. The banning of lead in house paint will be a protective measure for the future, but existing houses with lead paint still cause a hazard to children living in those houses, and to painters stripping this paint off (Cairns et al., 1979).

The criteria for acceptability depend on the type of effect that is in question. It may be that workers would accept up to 5 percent or 10 percent having irritation of the throat or other annoyance effects from fumes, but if these fumes cause cancers, it is likely that the acceptable response rate is much lower. Usually, there is not enough data on the response rates at very low doses and the evaluations will be approximate. For cancer, a linear doseresponse relationship down to dose zero is considered the best available estimate (Interagency Regulatory Liaison Group, 1979).

When estimating response rates it is important to keep in mind the combined response for all serious effects. In cases of asbestos exposure, for instance, about half of the increase in mortality among the asbestos-exposed, is due to lung cancer (Hammond et al., 1979), with the remaining hyper-mortality equally distributed between mesothelioma, asbestosis, and gastro-intestinal cancer (Hammond et al., 1979). If the acceptable response rate for asbestos-induced deaths is $0.1 / 1000$ we could not accept a higher death rate than 0.05 / 1000 for lung cancer and $0.016 / 1000$ for each of the other causes of death.

The criteria for acceptability are very seldom quantitatively analysed in the standard setting procedure. It is true that we have very little quantitative information at the low response rates after exposure to most chemicals, but the mathematical procedures used in standard setting for radiation hazards (Fremlin, 1980) could be used also for other occupational health hazards.

The criteria for acceptability should be laid down by the worker's organisations after consulting all relevant information about the hazard. These criteria would be based on the worker-perceived need for protection. As society develops, so also will the perception of health develop and the criteria for acceptability of standards are likely to change; most often the standards would be made stricter.

\section{A health standard and an administrative standard}

All countries that have standards as numerical figures for the concentration of chemicals in air or in some biological material do give only 1 figure as the long term exposure standdard. Sometimes short term exposure standards (STEL) or "ceiling values" (MAC) are also stated. If the concentration measured according to an approved method is above the set 
level, then it is considered that the particular workplace is not meeting the standard. In some cases, figures just below but close to the standard would require additional testing. As the criteria for acceptability are usually not explained in conjunction with the standard given, it is not clear what level of protection is achieved. Different countries have different standards and the official position is often that exposures below the standard are "safe".

The concept of 2 standards in which 1 is a standard purely based on health considerations and the other is an administrative standard which takes into consideration political, social and economic factors in the individual country, has been discussed among occupational health scientists for some years. A World Health Organisation study group recently described how such a 2-tiered system of "health-based" standards and administrative (or operational) standards could be developed (WHO, 1980). The health standard may be lower than exposure levels feasible at present but it will then serve as a goal for future developments in the industry. It is likely that international agreement can be reached on many health-based standards, whereas the administrative standards may vary from country to country depending on local conditions. This dual system gives the workers the advantage of knowing the degree of local politico-social adjustment of the standard.

The preamble to the report from the World Health Organisation study group (WHO, 1980) states that "the term recommended health-based occupational exposure limit represents in the opinion of the study group, levels in workroom air at which there is no significant risk of adverse health effects". The study group did not specify exactly what they meant with "no significant risk", but it can be understood from the presentation of health-based standards for specific metals later in the report (WHO, 1980), that they are considering very low response rates even for early biochemical changes.

World Health Organisation health-based standards have also been proposed for certain solvents (WHO, 1981) and pesticides (WHO, 1982). These standards are useful guidelines for the goals that workers organisations may aim for in the standard setting procedure.

\section{Replacement of ACGIH-List now used as world-wide reference standard}

The ACGIH made a valuable contribution to occupational health when they established a list of threshold limit values, or as they were then called, maximum allowable concentrations (MAC), more than 30 years ago (ACGIH, 1947). An MAC-list had been established in the Soviet Union before 1930, but it had not received general acceptance by industrial hygienists. In those early days, most governments had no occupational health standards. The guidelines given by the ACGIH TLVs have certainly contributed to improvements in the occupational environment. The ACGIH TLVs have the advantage of being supported by published documentation (ACGIH, 1982b) which is lacking for government standards in a number of countries. Therefore it is much easier to assess the protection given by ACGIH TLVs than by some government standards.

Many countries now adopt their own list of occupational health standards. However, as is seen in a document from the International Labour Organisation (ILO, 1981) some countries use the ACGIH TLVs without amendments or with minor amendments as their official national occupational health standards. Among those countries are the United Kingdom, Australia and New Zealand.

When OSHA was established in the United States, the ACGIH TLVs were adopted as official United States occupational health standards. With the support of toxicological and epidemiological research and review work by National Institute of Occupational Safety and Health, the standards for individual chemicals have been progressively reviewed by OSHA. Up to 1977 , such reviews have been carried out for 70 chemicals and in 40 cases the new proposed standards were decreased. In only 1 case was the standard increased (NIOSH, 1977).

It is clear from the documentation of the TLVs (ACGIH, 1982b) that the level of protection given by some ACGIH standards is not great. Let us take trichloroethylene as an example. Trichloroethylene is an organic solvent widely used in industry. The ACGIH and New Zealand TLV in 1983 is $535 \mathrm{mg} / \mathrm{m}^{3}$. Other exposure limits are lower: World Health 
Organisation health-based limits $=135$, Sweden $=110$, Poland $=54$ and USSR $=11 \mathrm{mg} / \mathrm{m}^{3}$. In the ACGIH documentation (ACGIH, 1982b) some studies showing serious health effects at very high exposures are quoted and some studies report no effects at $535 \mathrm{mg} / \mathrm{m}^{3}$. On the other hand, 1 study quoted reported symptoms of abnormal fatigue, irritability, headache, gastric disturbance, and intolerance to alcohol at lower air levels. Other studies found a variety of nervous disturbances at $210 \mathrm{mg} / \mathrm{m}^{3}$ and sleepiness at average exposures of $54 \mathrm{mg} / \mathrm{m}^{3}$. Liver cancers have been induced by trichloroethylene in rats, but have not been found yet in workers. Nevertheless, ACGIH concludes that "a TLV of $270 \mathrm{mg} / \mathrm{m}^{3}$ is recommended to provide workers with adequate protection against the toxic effects".

It is surprising that ACGIH considers that $270 \mathrm{mg} / \mathrm{m}^{3}$ gives "adequate" protection in light of the studies they refer to. Are the nervous disturbances irrelevant because they are "subjective" and may occur among unexposed people? Is there a "safety margin" for the more serious effects?

It all comes back to the criteria for acceptability of a standard. Employers may be willing to accept a higher degree of hazard than the workers themselves would accept. The ACGIH TLVs compromise between considerations of health and of the economy and technological processes in the industry. As seen from the example of vinyl chloride (Freiesleben, 1979), even a very strict occupational standard can be achieved if there is enough incentive for the industry to develop new low-exposure technology.

The ACGIH TLV list is used world-wide as a reference list for occupational standards. It has been abandoned in the United States for those chemicals. In the interest of workers' health, it is time that it also was abandoned in other countries. A new approach for worldwide guidelines for occupational standards is needed. The publication of World Health Organisation health-based permissible levels is a step in the right direction.

\section{Enforcement}

A standard is not worth very much if it is not enforced. This again is an area where the worker himself/herself could be given a much greater role than at present. The system of workers' health and safety representatives had been developed in Sweden by 1949 . These representatives had duties to assist in the enforcement of safety regulations in the factory. They also had rights to be informed about health and safety aspects of their work and to be involved in decisions about their environment. In 1972, the Swedish Workers' Protection Act was thoroughly revised and expanded the rights of these representatives. They were given the right to be informed about any future changes in the factory relevant to worker's health and safety, the right to take part on an equal basis in a factory health and safety committee, the right to take as much paid time as they felt needed for their health and safety to work and the right to stop the work if it caused immediate serious danger to any workers. The Swedish law was again revised and simplified in 1977 but the basic rights of the workers' representatives remained the same.

The other Scandinavian countries have similar provisions for health and safety representatives and these have recently been introduced in Britain. In Canada several provinces have occupational safety and health acts which spell out the workers' rights to refuse to carry out dangerous work.

The workers' involvement in the enforcement procedure is essential as they are the people to suffer if the enforcement is inadequate. In New Zealand it is common for health and factory inspectors to visit workplaces without introducing themselves to union delegates or shop-floor workers and without reporting to workers the results of the inspection (as reported by most participants in the union health and safety seminars I have attended). One step towards more worker involvement in enforcement would be for these inspectors always to take the union delegate along in the inspection.

Learning more about the work of the inspectors would give these delegates first-hand experience of the collection of data on exposure levels and health effects. This would give them valuable experience which would facilitate their active participation in the setting 
of occupational health standards.

\section{References}

ACGIH (American Conference of Governmental Industries Hygienists) (1947) 1947 MAC values Industrial hygiene newsletter $7: 15-16$.

ACGIH (1982a) TLVs. Threshold Limit Values for chemical substances and physical agents in the workroom environment with intended changes for 1982 Cincinatti.

ACGIH (1982b) Documentation of the Threshold Limit Values Cincinatti.

Ashford, N. (1979) Economic consideration in the establishment of standards. In SOEH (1979).

Bingham, E. (1979) Improving occupational health regulations. In SOEH (1979).

Cairns, L. et al (1979) The hazard of repainting an old house : case report of family and pets exposed to lead New Zealand medical journal $90: 493-496$.

Englund, A. (1979) The feasibility of banning asbestos : The Scandinavian experience. In SOEH (1979).

Freiesleben, W. (1979) A societal perspective on vinyl chloride regulation. In SOEH (1979)

Fremlin, J.H. (1980) Health risks from low level radiation Ambio 9 : 60-65.

Hammond, E.C. et al (1979) Asbestos exposure, cigarette smoking and death rates Annals of the New York Academy of Science 330 : 473-490.

ILO (1981) Occupational exposure limits for airborne toxic substances. Geneva.

Interagency Regulatory Liaison Group (1979) Scientific bases for identification of potential carcinogens and estimation of risks Journal of the National Cancer Institute 63 : $241-268$.

Locke, J. (1979) Enforcement of and compliance with standards. In SOEH (1979).

NIOSH (National Institute of Occupational Safety and Health) (1977) Summary of NIOSH recommendations for occupational health standards Washington.

OSHA (1978) Occupational exposure to lead. Final standard (Fed. Reg. 43, 52952-53014). Washington.

SOEH (Society for Occupational and Environmental Health) (1979) International Commission Workshop on Occupational Health Standards, Mont St Marie, Quebec, November 8-11 : Proceedings. Washington.

WHO (1980) Health-based permissible levels of occupational exposure to heavy metals Geneva.

WHO (1981) Recommended health-based limits in occupational exposure to selected organic solvents. Geneva.

WHO (1982) Recommended health-based limits in occupational exposure to pesticides Geneva. 